\title{
Heterogeneous integration of GaInAsSb p-i-n photodiodes on a silicon-on-insulator waveguide circuit
}

\author{
N. Hattasan, A. Gassenq, L. Cerutti, J.B. Rodriguez, E. Tournié, G. Roelkens
}

\begin{abstract}
We report the integration of GaInAsSb p-i-n photodiodes on a silicon-on-insulator waveguide circuit. The device operates with low dark current $(1.13 \mu \mathrm{A}$ at $-0.1 \mathrm{~V})$ at room temperature. A high responsivity of $0.44 \mathrm{~A} / \mathrm{W}$ is measured at 2.29 $\mu \mathrm{m}$. This yields $1.63 \times 10^{9} \mathrm{cmHz}^{1 / 2} / \mathrm{W}$ of Johnson-noise-limiteddetectivity.
\end{abstract}

Index Terms-photodiode, GaInAsSb, heterogeneous integration

\section{INTRODUCTION}

S everal bio-molecules and gases such as glucose, $\mathrm{CH}_{4}, \mathrm{CO}_{2}$ and $\mathrm{CO}$ have strong overtone and combination absorption lines in the near and mid-infrared, particularly in the $2-2.5 \mu \mathrm{m}$ wavelength range. In this wavelength region, absorption spectroscopy can be used to analyze the composition of an analyte through the absorption signatures of the molecules. A number of sources and detectors have been proposed over the past few years for this goal [1]-[3]. However, these are discrete opto-electronic components. Integration of such components on a waveguide platform would open a whole new range of applications for mid-wave infrared systems. Silicon photonics has advantages in terms of cost and CMOS compatible fabrication for photonic integrated circuits in the telecommunication wavelength range [4]-[5]. Given its transparency from 1.2 to $3.5 \mu \mathrm{m}$, it is possible to realize integrated spectroscopic systems on this platform by combining active opto-electronic devices on SOI passive waveguide circuits. Several works have been reported towards this goal, for example, the integration of metal-semiconductormetal and Ge photodetectors, using different integration techniques [6]-[7]. The realizations so far are however focused on telecommunication applications in the $1.55 \mu \mathrm{m}$ wavelength range.

In this paper we present the first heterogeneous integration of GaInAsSb p-i-n photodiodes (grown latticed matched on a $\mathrm{GaSb}$ substrate) on silicon-on-insulator (SOI) waveguide circuits. Our integration approach is based on adhesive bonding using the DVS-BCB (Benzocyclobutene) as an adhesive bonding agent.

Manuscript received June 27, 2011. This work was supported in part by Glucosens project Grant IWT-SBO and Miracle project. N. Hattasan is with Photonics Research Group, Intec department, Ghent University-IMEC and Center for Nano- and Biophotonics (NB-Photonics), Ghent, 9000 Belgium (phone: +32 (0) 9264 3318; fax: +32 (0) 9264 3593; e-mail: nannicha.hattasan@ intec.ugent.be).
A dark current of $1.13 \mu \mathrm{A}$ at $-0.1 \mathrm{~V}$ corresponding to a current density of $186 \mathrm{~mA} / \mathrm{cm}^{2}$ and a responsivity of $0.44 \mathrm{~A} / \mathrm{W}$ at $2.29 \mu \mathrm{m}$ are obtained, resulting in a $\sim 24 \%$ external quantum efficiency. The device operates at room temperature.

\section{DESIGN AND SIMULATION}

The device schematic is shown in Fig. 1. It consists of a $3 \mu \mathrm{m}$ wide by $220 \mathrm{~nm}$ thick silicon-on-insulator waveguide onto which a GaInAsSb epitaxial layer stack is bonded using DVS-BCB adhesive bonding. Light is coupled from the SOI waveguide into the photodetector using evanescent coupling. Optimal coupling can be achieved by controlling the phase matching between the SOI waveguide and the photodiode waveguide. The simulation of the coupling efficiency as a function of the photodetector thickness is carried out using a full-vectorial 2D eigenmode expansion method [8]. The simulation result is shown in Fig. 2 for a $20 \mu \mathrm{m}$ long device. It shows that the maximum absorption is achieved when the thickness of the photodiode is such that the waveguide mode phase matches with the Si waveguide mode.

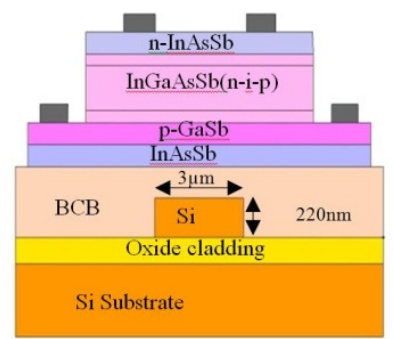

Fig.1 Cross-section schematic of the device

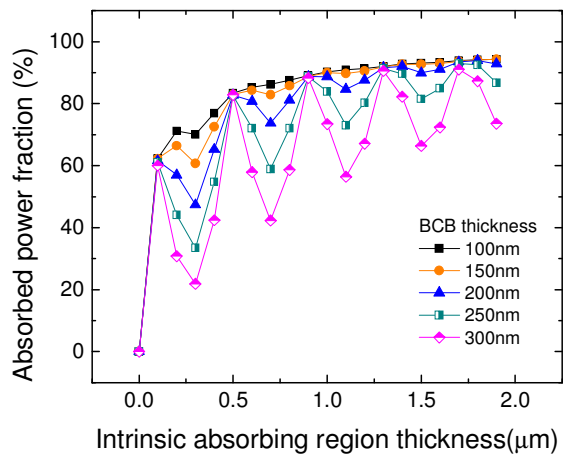

Fig. 2 Simulation showing the impact of absorbing region thickness and BCB thickness on detection efficiency 
The epitaxial stack consists of 50nm p-doped $\left(1.0 \times 10^{18} \mathrm{~cm}^{-3}\right)$ $\mathrm{GaSb}$ and a 50nm p-doped $\left(1.0 \times 10^{18} \mathrm{~cm}^{-3}\right)$ $\mathrm{Ga}_{0.79} \mathrm{In}_{0.21} \mathrm{As}_{0.19} \mathrm{Sb}_{0.81}$ layer as the $\mathrm{p}$-zone of a $\mathrm{p}$-i-n layer stack. A not intentionally doped 500nm thick $\mathrm{Ga}_{0.79} \mathrm{In}_{0.21} \mathrm{As}_{0.19} \mathrm{Sb}_{0.81}$ layer is used for the intrinsic absorbing region which is indicated as the optimum point from the simulation. The n-type region consists of $50 \mathrm{~nm}$ $\mathrm{Ga}_{0.79} \mathrm{In}_{0.21} \mathrm{As}_{0.19} \mathrm{Sb}_{0.81}$ and $50 \mathrm{~nm}$ InAs ${ }_{0.91} \mathrm{Sb}_{0.09}$. Both are doped to $1.0 \times 10^{18} \mathrm{~cm}^{-3}$. An InAs $\mathrm{As}_{0.91} \mathrm{Sb}_{0.09}$ layer is chosen as n-contact because of its lower bandgap $(0.35 \mathrm{eV})$ and low contact resistance [9]-[10].

The energy band diagram is presented in Fig. 3. The diffusion of minority carriers is prevented on the p-type side by the use of a wide bandgap GaSb laser. The cut off wavelength of this epitaxial stack is estimated to be $2.5 \mu \mathrm{m}$.

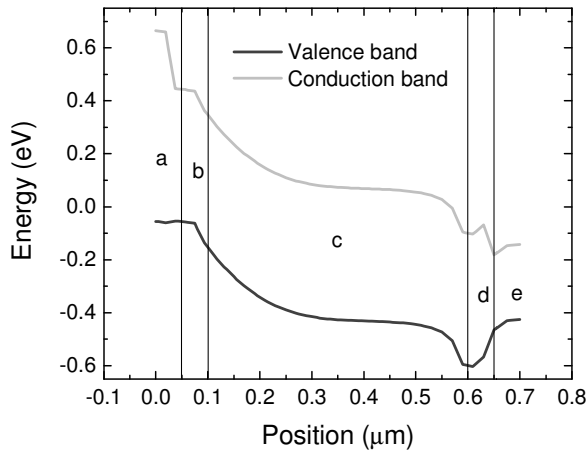

Fig.3 Energy band diagram of the integrated photodetector indicating region (a) as GaSb p-doped, (b)(c)(d) as p-i-n GaInAsSb respectively and (e) as InAsSb n-doped

\section{DEVICE FABRICATION}

The fabrication process can be divided into 3 parts: SOI waveguide fabrication, epitaxial growth, and photodiode fabrication. SOI waveguides are processed with standard CMOS technology. 193nm deep UV lithography is used for pattern definition and the waveguides are dry etched [11].

The epitaxial stack is grown by MBE (Molecular beam epitaxy) on a n-type GaSb substrate [12]. Adhesive bonding is used for the integration of the epitaxial layers onto the SOI chip [13]. BCB is applied on the SOI chip by spin coating. The epitaxial layer stack is then attached upside down onto the SOI waveguide circuit. The BCB is then cured at $250{ }^{\circ} \mathrm{C}$ for 1 hr. The bonding thickness can be varied by diluting the DVSBCB solution with varying volumes of mesitylene. Successful bonding of the GaSb-based epitaxy with $68 \mathrm{~nm}$ of DVS-BCB was demonstrated. After the bonding process, the $\mathrm{GaSb}$ substrate is removed by wet etching with a mixture of $\mathrm{HF}$, $\mathrm{CrO}_{3}$ and water $(1: 1: 3 \mathrm{v} / \mathrm{v})$ at room temperature, using the InAsSb layer as an etch stop layer. InAsSb is removed before n-contact deposition by using a mixture of citric acid and hydrogen peroxide $(100: 50 \mathrm{v} / \mathrm{v})$ The mesa is formed by a combination of both dry $\left(\mathrm{CH}_{4}: \mathrm{H}_{2}\right)$ and wet etching (citric acid: $\mathrm{H}_{2} \mathrm{O}_{2}: \mathrm{H}_{3} \mathrm{PO}_{4}: \mathrm{H}_{2} \mathrm{O}$ 55:5:3:220 v/v) to reduce the dark current. $\mathrm{Ti}(2 \mathrm{~nm}) / \mathrm{Pt}(35 \mathrm{~nm})$ and $\mathrm{Au}(100 \mathrm{~nm})$ is deposited using e-beam evaporation for both contacts. BCB $(1.3 \mu \mathrm{m}$ thick $)$ is then spinned coated on the sample and cured at $250{ }^{\circ} \mathrm{C}$ for $1 \mathrm{hr}$ to passivate the device. Fig. $4 \mathrm{a}$ is a SEM cross section image of the fabricated photodetector, showing undercut due to the wet etching process. The bonding thickness for the reported devices is $258 \mathrm{~nm}$. The original process scheme included the removal of the InAsSb cap layer to obtain a clean surface before bonding. However, this created a hydrophilic surface which prevented good bonding with BCB. Therefore, the InAsSb cap layer was kept in this experiment. The mesa is 9 $\mu \mathrm{m}$ wide and $50 \mu \mathrm{m}$ long (Fig. 4b).

\section{MEASUREMENT RESULTS}

The experimental setup consists of a continuous wave shortwave-infrared tunable laser which is coupled to a single mode fiber. After polarization control, TE-polarized light from a single mode fiber is injected into the SOI waveguide through a grating coupler structure defined in the silicon waveguide layer. The gratings have approximately $-9 \mathrm{~dB}$ peak coupling efficiency at $2.27 \mu \mathrm{m}$ with a $200 \mathrm{~nm} 3 \mathrm{~dB}$-bandwidth. The distance between the grating coupler and the device is 400 $\mu \mathrm{m}$. Therefore, the loss due to the propagation in the waveguide can be neglected. The reference signal before injecting into the chip is measured from single mode fiber using an optical spectrum analyzer (AQ6375 from Yokogawa).

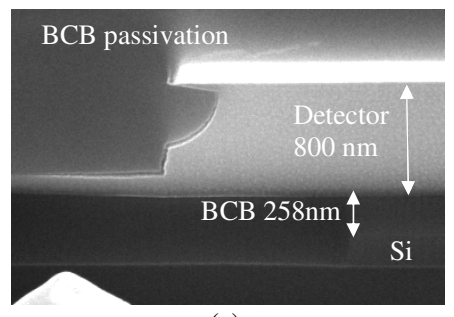

(a)

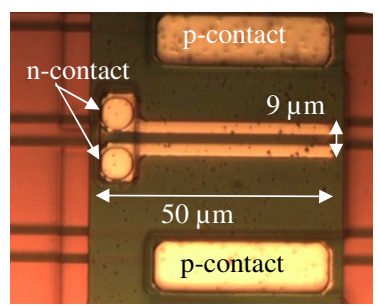

(b)
Fig. 4 a) Cross-section SEM image b) Optical image of the device

The photoresponse measured at $2.25 \mu \mathrm{m}$ at different fiber input power levels is shown in Fig. 5. Good linearity is obtained over a $12 \mathrm{~dB}$ input power range in Fig. 5. The dark current at $-0.1 \mathrm{~V}$ is $1.13 \mu \mathrm{A}$ at room temperature. This corresponds to a current density of $186 \mathrm{~mA} / \mathrm{cm}^{2}$. We performed initial investigations on $\mathrm{R}_{0} \mathrm{~A}$ vs perimeter-to-area ratio of the photodiode; we obtain an $\mathrm{R}_{0} \mathrm{~A}$ ranging from 1.6 (for a $180 \mu \mathrm{m}$ by $180 \mu \mathrm{m}$ device) to $0.53 \Omega . \mathrm{cm}^{2}$ (for a $60 \mu \mathrm{m}$ by $60 \mu \mathrm{m}$ device). It shows a strong dependence on perimeterto-area which suggests that side wall leakage is a limiting factor. This can be improved by changing the mesa etching condition, for example, by wet etching and using a passivation process such as applying ammonia sulfide before BCB passivation.

In this experiment, we obtain a peak fiber to detector responsivity of $0.06 \mathrm{~A} / \mathrm{W}$ at $2.29 \mu \mathrm{m}$. Based on our initial measurement results of grating couplers, we can estimate coupling loss at this wavelength to be larger than $-9 \mathrm{~dB}$ at this wavelength. Therefore, we obtain a minimum peak responsivity of $0.44 \mathrm{~A} / \mathrm{W}$ corresponding to $24 \%$ quantum efficiency.The dark current at as a function of temperature is shown in Fig. 6 (at $-0.5 \mathrm{~V}$ ). It decreases significantly as the 
temperature decreases.

The NEP (noise equivalent power) at $0 \mathrm{~V}$ bias as a function of the temperature is calculated [14] and plotted in Fig. 7. It decreases gradually due to the increase of shunt resistance when the temperature decreases.

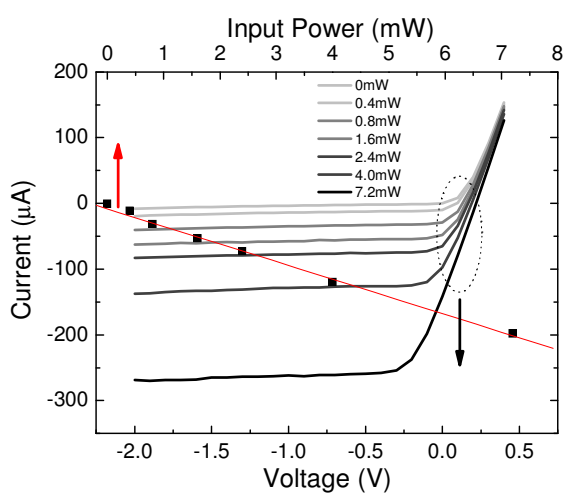

Fig. 5 V-I characteristics at different fiber input power levels measured at $2.25 \mu \mathrm{m}$ wavelength. ( $\mathrm{\circ}$ ) Photocurrent measured at $-0.1 \mathrm{~V}$ with different input power levels showing good linearity

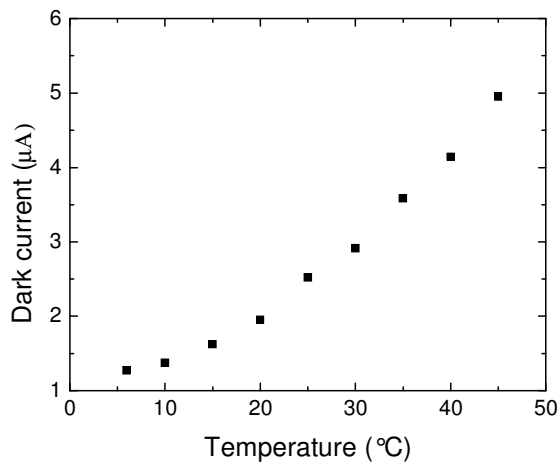

Fig.6 Dark current at $-0.5 \mathrm{~V}$ at different temperatures.

The Johnson-noise limited NEP is equal to $1.51 \times 10^{-12}$ $\mathrm{W} / \mathrm{Hz}^{1 / 2}$ obtained at $25^{\circ} \mathrm{C}$, corresponding to a responsivity of $0.44 \mathrm{~A} / \mathrm{W}$. This represents a Johnson noise limited detectivity D* of $1.63 \times 10^{9} \mathrm{cmHz}^{1 / 2} / \mathrm{W}$. An $\mathrm{R}_{0} \mathrm{~A}$ of $0.25 \Omega . \mathrm{cm}^{2}$ is obtained on these devices. The overall performance of this device is not as good as the previous reports on stand-alone non-integrated devices [3], [15]. This is due to the smaller size of the current device which experiences more side wall and therefore results in higher leakage current.

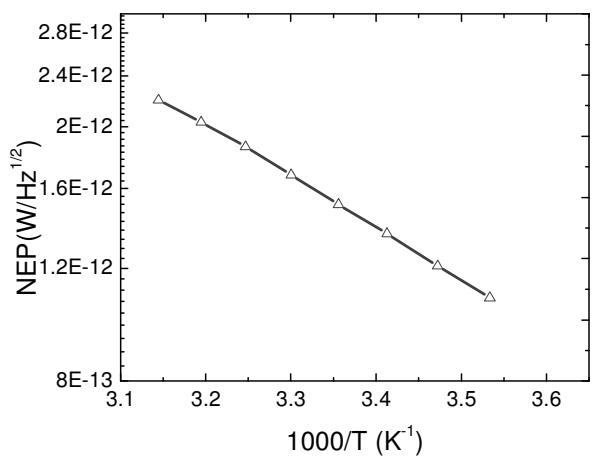

Fig.7 Johnson noise limited NEP as a function of temperature

This implies that miniaturization comes at a cost of a decreased detectivity, however, as discussed; process optimization can alleviate this performance degradation compared to stand-alone large area devices.

\section{CONCLUSION}

In summary, we have demonstrated the first GaInAsSb p-i-n photodetector integrated on and coupled to an SOI waveguide circuit. Our design and fabrication process shows mid-infrared integrated photodetectors with high responsivity and very low dark current. This makes it suitable for integrated spectroscopic system.

\section{ACKNOWLEDGMENT}

The author would like to thank S. Verstuyft and Z. Yu for processing assistance and L. Van Landschoot for SEM images

\section{REFERENCES}

[1] D. Barat, J. Angellier, A. Vicet and Y. Rouillard, "Antimonide-based lasers and DFB laser diodes in the 2-2.7 $\mu \mathrm{m}$ wavelength range," Appl. Phys. B, Vol. 90, No. 2, 201-204 (2008).

[2] J. A. Gupta, P. J. Barrios, J. Lapointe, G. C. Aers, and C. Storey, "Single-mode $2.4 \mu \mathrm{m}$ InGaAsSb/AlGaAsSb distributed feedback lasers for gas sensing," Appl. Phys. Lett., Vol. 95, No. 4, 041104, 2009.

[3] H. Shao, A. Torfi, W. Li, D. Moscicka and W. I. Wang, "High detectivity AlGaAsSb/InGaAsSb photodetectors grown by molecular beam epitaxy with cutoff wavelength up to $2.6 \mu \mathrm{m}$," J. Cryst. Growth, Vol. 311, pp. 1893-1896, March 2009.

[4] L. Liu, G. Roelkens, J. Van Campenhout, J. Brouckaert, D. Van Thourhout and R. Baets, "III-V/silicon-on-insulator nanophotonic cavities for optical network-on-chip," J. Nanosci. Nanotechnol., Vol. 10, p.1461-1472, 2010.

[5] G. Roelkens, L. Liu, D. Liang, R. Jones, A. Fang, B. Koch and J. Bowers, "III-V/silicon photonics for on-chip and inter-chip optical interconnects," Laser Photonics Rev., Vol. 4, No. 6, pp. 751-779, Nov 2010 .

[6] J. Brouckaert, G. Roelkens, D. Van Thourhout and R. Baets, "Compact InAlAs/InGaAs Metal-Semiconductor-Metal Photodetectors Integrated on Silicon-on-Insulator Waveguides," IEEE Photon. Technol. Lett., vol. 19, No. 19, p.1484-1486, 2007.

[7] S. B. Samavedam, M. T. Currie, T. A. Langdo, and E. A. Fitzgerald , "High-quality germanium photodiodes integrated on silicon substrates using optimized relaxed graded buffers," Appl. Phys. Lett., Vol. 73, No. 15, Aug 1998.

[8] http://camfr.sourceforge.net

[9] I. Vurgaftman, J. R. Meyer and L. R. Ram-Mohan, "Band parameters for III-V compound semiconductors and their alloys," J. Appl. Phys., Vol. 89, No. 11, pp. 5816-5862, June 2011.

[10] C. Lauer, O. Dier, M.C. Amann, "Low-resistive metal $/ n^{+}-\mathrm{InAsSb} / \mathrm{n}$ GaSb contacts," Semicond. Sci. and Technol., Vol. 21, pp.1274-1277, July 2006.

[11] W. Bogaerts, P. Dumon, D. Taillaert, V. Wiaux, S. Beckx, B. Luyssaert, J. Van Campenhout, D. Van Thourhout, and R. Baets, "SOI Nanophotonic Waveguide Structures Fabricated with Deep UV Lithography," Phot. Nano. Fund. Appl., Vol.2, No. 2, pp. 81-86, 2004.

[12] E. Tournié and A. Trampert, "MBE growth and interface formation of compound semiconductor heterostructures for optoelectronics," Phys. Stat. Sol. Vol. (b) 244, No. 8, pp.2683-2696, 2007.

[13] G. Roelkens, J. Brouckaert, D. Van Thourhout, R. Baets, R. Notzel and M. Smit, "Adhesive Bonding of InP/InGaAsP Dies to Processed Siliconon-Insulator Wafers using DVS-bis-Benzocyclobutene," J. Electrochem. Soc., Vol. 153, No. 12, pp. G1015-G1019, 2006.

[14] F. Trager, Springer Handbook of Lasers and Optics. New York: Springer, 2007, ch. 9.

[15] J. P. Prineas, J. Jager, S. Seyedmohamadi, J. T. Olesberg, "Leakage mechanism and potential performance of molecular-beam epitaxially grown GaInAsSb $2.4 \mu$ m photodiode detectors," J. Appl. Phys., Vol. 103, No. 104511, 2008. 